\title{
DIAGNOSED AN ISLANDER
}

\section{Josie Crawley}

Am I cursed an Island dweller

or blessed a frequent flyer

castaway where quickness of thought

fatigues mis-fired neurons.

Such synaptic chaos

celebrates successful completion of each day,

careful allocation of energy and need, energy and want,

wanted, longed for energy.

Today no blueprint for tomorrow

Out there for those not marooned on islands

the world speedily spins

fragile plans with gossamer threads of health -

wealth, worth, career, status

eggshell futures for the sanguine.

Island life illuminates the moments that blur,

do mainlanders revel in an obedient bladder, navigating a step, the supportive joy of a pillow behind the head;

small things that make a day

or does the nuanced challenge of being alive rush past. 


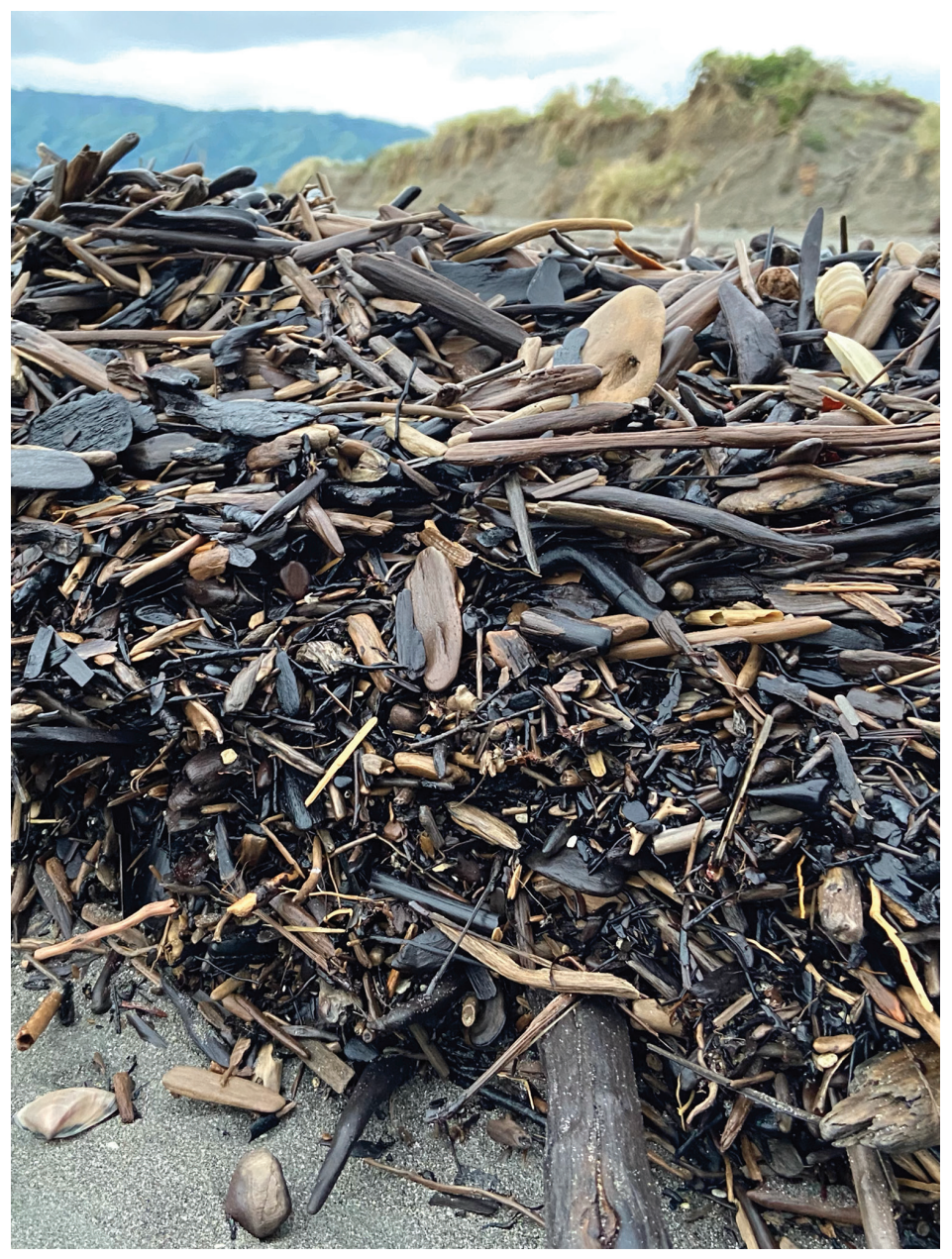

Figure I. Kapiti Coast Drift. Source: Author

Josephine Crawley (10) https://orcid.org/0000-0003-101I-3335, RN, BA, MEd, GCTLT is a principal lecturer at the School of Nursing, Otago Polytechnic Ltd. She has been involved in nurse education in both the community and institutions for over 25 years. Her research platform explores the place of narratives within nursing education for reflection, to build compassionate care and to research the client and nurse experience. She has published in a variety of academic journals, case studies, presented internationally, co-edited a book and her poetry has been included in a collection of poems by Aotearoa New Zealand Nurses.

Correspondence to: Josie Crawley, Otago Polytechnic | Te Kura Matatini ki Otago. Email: josie.crawley@op.ac.nz 